\title{
Investigating a pathogenic role for TXNDC5 in rheumatoid arthritis
}

\author{
Xiaotian Chang ${ }^{1 *}$, Yan Zhao ${ }^{1}$, Xinfeng Yan², Jihong Pan ${ }^{1}$, Kehua Fang ${ }^{1}$ and Lin Wang ${ }^{1}$
}

\begin{abstract}
Introduction: Expression of TXNDC5, which is induced by hypoxia, stimulates cell proliferation and angiogenesis. Our previous study detected increased TXNDC5 expression in the synovial tissues of rheumatoid arthritis (RA) patients using proteomic methods. The current study investigated a pathogenic role for TXNDC5 in RA.

Method: Expression of TXNDC5 in synovial membranes was quantitatively analyzed by immunohistochemistry, Western blotting and real-time polymerase chain reaction (PCR). Serum TXNDC5 levels and serum anti-TXNDC5 antibody levels were determined using sandwich enzyme-linked immunosorbent assay (ELISA). A total of 96 single nucleotide polymorphisms (SNPs) in or near the TXNDC5 gene were genotyped using custom-designed Illumina 96-SNP VeraCode microassay. Allele frequencies and genotype frequencies of SNPs were assessed using a casecontrol design in a cohort of 267 Chinese patients with RA, 51 patients with ankylosing spondylitis (AS) and 160 healthy controls. Additional genotyping of 951 patients with RA and 898 healthy controls was performed for four SNPs (rs2277105, rs369086, rs443861 and rs11962800) using the TaqMan method.
\end{abstract}

Results: Real-time PCR, Western blotting and immunohistochemistry detected significantly higher TXNDC5 expression in the synovial tissues of RA patients compared to samples from patients with osteoarthritis (OA) or AS. ELISA detected significantly higher levels of TXNDC5 in the blood of RA patients compared to OA, AS and systemic lupus erythematosus patients, and healthy controls. ELISA did not detect significantly different levels of antiTXNDC5 antibody in the blood of RA, OA and AS patients and healthy controls. A total of 9 SNPs (rs9505298, rs41302895, rs1225936, rs1225938, rs372578, rs443861, rs408014, rs9392189 and rs2743992) showed significant association with RA, while 16 SNPs (rs1044104, rs1225937, rs1225938, rs372578, rs89715, rs378963, rs1225944, rs1225947, rs1238994, rs369086, rs408014, rs368074, rs1225954, rs1225955, rs13209404 and rs3812162) showed significant association with AS. Taqman SNP assay demonstrated that rs443861 has an association with RA, which correlates with the microassay results.

Conclusions: TXNDC5 is up-regulated in synovial tissues of RA patients. TXNDC5 has a genetic effect on the risk of RA and AS.

\section{Introduction}

The thioredoxin domain, containing five (TXNDC5) proteins, also named ERp46, has a protein disulfide isomerase (PDI) domain that exhibits a high sequence similarity to thioredoxin, a catalyst of the rate limiting reaction of disulphide bond formation, isomerisation and reduction $[1,2]$. Yeast complementation tests showed that TXNDC5

\footnotetext{
* Correspondence: changxt@126.com

'National Laboratory for Bio-Drugs of Ministry of Health, Provincial Laboratory for Modern Medicine and Technology of Shandong, Research Center for Medicinal Biotechnology, Shandong Academy of Medical Sciences, Jingshi Road 18877, Jinan, Shandong, 250062. P. R. China Full list of author information is available at the end of the article
}

can conduct PDI functions in vivo [3]. Indirect immunofluorescence microscopy and subcellular fractionation studies have shown that TXNDC5 is present both in the endoplasmic reticulum and the plasma membrane [4]. TXNDC5 is highly expressed in endothelial cells during hypoxic conditions, and plays important roles in antioxidative injury, anti-anoxia-induced apoptosis and the promotion of cell proliferation $[1,2]$.

Abnormal proliferation of synovial fibroblasts and increased angiogenesis are pathological characteristics of rheumatoid arthritis (RA), an autoimmune disease that results in inflammation of the joints [5]. Using a proteomics approach, we detected increased TXNDC5 expression 
in synovial tissues from RA patients [6]. Furthermore, we detected significantly elevated levels of TXNDC5 in the synovial fluid of patients with RA [6]. RA is thought to decrease the oxygen supply, leading to synovial hypoxia and hypoperfusion $[7,8]$. Hence, we believe that up-regulation of TXNDC5 may play an important role in the pathogenesis of RA in the hypoxic environment.

In the current study, we quantitatively analyzed the expression of TXNDC5 in synovial tissues on both transcriptional and translational levels. We also examined TXNDC5 levels in the blood of RA patients using sandwich ELISA. To determine genetic effects of TXNDC5 on RA, we conducted Illumina GoldenGate assays to identify potential associations between TXNDC5 polymorphisms and RA. SNPs, including tag SNPs, SNPs in promoter regions, SNPs in untranslational regions (UTRs), SNPs in exons and SNPs within proximity to exons of the TXNDC5 gene were genotyped in RA populations, and potential associations were determined by case-control study and haplotype analysis.

\section{Materials and methods}

\section{Sample collection of synovial tissues and blood}

Synovial tissue samples were collected during knee joint replacement surgery from patients with RA $(n=10,25$ female, 23 to 70 years old, mean 50 ) and patients with osteoarthritis (OA) $(n=10,6$ female, 41 to 77 years old, mean 60). Synovial tissue samples from patients with AS ( $n=10,3$ female, 28 to 54 years old, mean 35 ) were collected during hip joint replacement surgery. The diagnosis of RA was made according to the criteria of the American College of Rheumatology. The patients with RA had disease durations of 3-to-10 years and were classified as having erosive RA (Larsen class IV to V). They had high levels of C-reactive protein (30 to $100 \mathrm{mg} / \mathrm{L}$, mean $24 \mathrm{mg} / \mathrm{L}$ ), anti-CCP (300 to 3,000 U/ml) and RF (160 to $2,560 \mathrm{U} / \mathrm{ml}$ ). AS patients had an average disease duration of seven years and were positive for HLA-B27 antigen. Their symptoms were consistent with the modified New York criteria for AS. Patients with AS and RA took disease-modifying antirheumatic drugs (DMARDs) before surgery. Patients with AS, RA and OA were also medicated with non-steroidal anti-inflammatory drugs (NSAIDs), which help reduce the pain and swelling of the joints, and decrease stiffness. All of AS and RA patients got treatment with DMARDs. Thus, the medical pretreatment does not influence the results and the experimental results are comparable. Additional file 1 in the supplementary materials summarizes the epidemiological data. All AS, RA and OA patients got treatment with NSAIDs. Synovial samples were dissected from connective tissues and immediately stored at $-80^{\circ} \mathrm{C}$ until used.

Peripheral blood samples were collected from patients with RA ( $n=267,183$ female) and AS ( $n=51,10$ female).
RA patients had a mean age of 51.7 years, while AS patients had a mean age of 35.9 years. The diagnosis of RA and AS was conducted as described above. Patients were selected from the same population living in the Shandong area of Northern China. A total of 160 (58 female) healthy individuals with a mean age of 48.0 years were blood donors; they did not have any personal or family history of serious illness. Control individuals were frequency matched to the expected age distribution of the cases and were from the same geographical area. Blood samples were put into Monovette tubes containing 3.8\% sodium citrate.

Both patients and healthy controls gave their written consent to participate in the study and to allow their biological samples to be genetically analyzed. The Ethical Committee of Shandong Academy of Medicinal Sciences approved this study.

\section{Western blot analysis}

Tissue samples weighing $200 \mu \mathrm{g}$ from RA, OA and AS patients were homogenized in Cell Lysis Solution (Sigma-Aldrich, St. Louis, MO, USA) and centrifuged at $16,000 \times \mathrm{g}$ for five minutes at $4^{\circ} \mathrm{C}$. Supernatants were collected after centrifugation, and protein concentrations were determined using the BCA Protein Assay Kit (Thermo Fisher Scientific, Rockford, IL, USA). Total protein was separated by sodium dodecyl sulphate polyacrylamide gel electrophoresis (SDS-PAGE) and trans-blotted onto nitrocellulose membranes (GE Healthcare, Piscataway, NJ, USA). Western blot analysis was conducted using anti-TXNDC5 antibody (Abcam, Cambridge, Cambridgeshire, UK)) at a 2,000-fold dilution. The antibody was raised in goats using an oligopeptide (SLHRFVLSQAKDEL) against TXNDC5. All primary and secondary antibodies were diluted in 5\% nonfat dry skim milk in TBST (Tris base $0.02 \mathrm{M}, \mathrm{NaCl} 0.137 \mathrm{M}$ in distilled water ( $\mathrm{pH} 7.6$ ), containing $0.1 \%$ Tween-20). Immunoreactive signals were detected with alkaline phosphatase-conjugated secondary antibodies and visualized using a Western blotting luminol reagent (GE Healthcare). Western blot images were acquired on a Typhoon Trio (GE Healthcare). Quantification was conducted using ImageQuant 5.2 software. Another membrane prepared by the same protocol was probed with anti-GADPH antibody (Santa Cruz Biotechnology, Santa Cruz, CA, USA) to normalize sample loading.

\section{Immunohistochemistry}

Tissue sections of synovial tissues from RA, OA and AS patients were de-paraffinized and re-hydrated by standard procedures. Before the anti-TXNDC5 antibodies were applied, tissue sections were heated at $95^{\circ} \mathrm{C}$ for 10 minutes in citrate buffer solution (Sigma) for antigen recovery and then incubated with an endogenous peroxidase inhibitor 
(Maixin-Bio, Fuzhou, Fujian, China) for 30 minutes at room temperature. After washing with PBS buffer $(\mathrm{NaCl}$ $0.132 \mathrm{M}, \mathrm{K} 2 \mathrm{HPO} 40.0066 \mathrm{M}, \mathrm{KH} 2 \mathrm{PO} 40.0015 \mathrm{M}$ in distilled water, $\mathrm{pH}$ 7.6), sections were incubated with antibodies directed against TXNDC5 (Abcam) overnight at $4^{\circ} \mathrm{C}$. Immunoreactions were processed using the UltraSensitive TM S-P Kit (Maixin-Bio) according to the manufacturer's instructions. Immunoreactive signals were visualized using DAB substrate, which stains the target protein yellow. Cell structures were counterstained with hematoxylin.

In order to determine antibody specificity and optimize antibody dilution, the tissue samples were incubated (1) with goat pre-immune serum (Maixin-Bio, China) or (2) treated by the modification buffer without addition of antibody.

\section{Immunofluorescent labeling}

Tissue sections were processed as described above. After three washes with PBS buffer, tissue sections were treated with goat pre-immune serum (Maixin-Bio, China) for 30 minutes to improve the specificity of the immunoreaction. Slides were incubated with anti-TXNDC5 antibody (Abcam) at $4^{\circ} \mathrm{C}$ for $12 \mathrm{~h}$ and then washed with PBS. TRITC 5-conjugated anti-goat IgG (Sigma-aldrich) was added to the slides, and slides were incubated for $40 \mathrm{~min}$ utes at room temperature. Immunofluorescence was conducted with a Nikon 50i fluorescence microscope (Nikon, Shinjuku, Tokyo, Japan). To determine antibody specificities and optimize antibody dilutions, a series of control slides were prepared as follows: primary antibodies only, secondary antibodies only and normal goat serum only. Expression levels of TXNDC5 were evaluated with SimplePCI (Hamamatsu Photonics, Sewickley, PA, USA), a semi-quantitative scoring system that analyzes the results of immunofluorescent labeling according to signal density.

\section{Real-time PCR}

Total RNA was isolated from the synovial tissues of RA, $\mathrm{OA}$ and AS patients using Trizol solution (Invitrogen Life Technologies, Carlsbad, California, USA) according to the manufacturer's protocol. Extracted total RNA was reversetranscribed in a final volume of $10 \mu \mathrm{l}$ using a RNA PCR Kit (TaKaRa, Katsushika, Tokyo, Japan). Real-time PCR reactions were conducted using the LightCycler 480 Instrument (Roche Molecular Biochemicals, Basel, Switzerland) and performed according to the manufacturer's protocol. Reactions were performed in a total volume of $10 \mathrm{ul}$, containing $1 \mathrm{ul}$ of cDNA, $5 \mathrm{ul}$ of SYBR Green Real-time PCR Master Mix (ToYoBo, Tokyo, Japan) and $1 \mathrm{ul}$ of each primer. PCR amplification cycles were carried out as follows: $10 \mathrm{~s}$ at $95^{\circ} \mathrm{C}, 40$ cycles of $5 \mathrm{~s}$ at $95^{\circ} \mathrm{C}$ and $31 \mathrm{~s}$ at $60^{\circ} \mathrm{C}$. For each sample, two reactions were performed at the same time. One reaction was performed to determine the mRNA level of the target gene, and the second was performed to determine level of $\beta$ actin. The experiment was performed in triplicate. PCR products were confirmed by melt curve analysis. Relative mRNA expression was calculated using the comparative threshold cycle $(\mathrm{Ct})$ method according to the following formula: Ratio $=2-\Delta \Delta \mathrm{Ct}=2-\Delta \mathrm{Ct}($ sample $)$, where $\Delta \mathrm{Ct}=$ $\mathrm{Ct}$ of target genes - Ct of endogenous control gene ( $\beta$ actin). The relative target gene expression was normalized in comparison to $\beta$-actin mRNA levels. Primer sequences for the amplification of human TXNDC5 were as follows: forward primer for TXNDC5, 5'-GGGTCAAGATCGCCG AAGTA-3'; reverse primer for TXNDC5, 5'-GCCTCCA CTGTGCTCACTGA-3'; forward primer for human $\beta$ actin, 5'-TGGCACCCAGCACAATGAA-3'; and reverse primer for human $\beta$-actin, 5'-CTAAGTCATAGTCCGCCTAGAAGCA-3'. Primer efficiency was determined by serially diluting a standard RT reaction product. PCR efficiency was automatically calculated according to the dilution curve by the instrument software. Primer specificity was determined by both gel electrophoresis and melt curve analysis. Levels of TXNDC5 are expressed as the median and range. Statistical differences were assessed using the Mann-Whitney U-test; $P<0.05$ was considered statistically significant.

\section{Sandwich ELISA detecting serum levels of TXNDC5}

Blood was collected from patients with RA $(n=96$, 75 females, 23 to 71 years old, mean 46$)$, OA ( $n=56$, 16 females, 50 to 86 years old, mean 62$)$, AS $(n=56$, 19 females, 28 to 51 years old, mean 34) and systemic lupus erythematosus (SLE $n=56,43$ females, 23 to 73 years old, mean 40$)$ as well as healthy controls $(n=48$, 24 female, 20 to 40 years old, mean 31). Blood samples were collected using vacuum blood collection tubes. Following centrifugation at $1,000 \times \mathrm{g}$ for 30 minutes, serum was collected and stored at $-80^{\circ} \mathrm{C}$ until use. We raised antibodies in rabbits using an oligopeptide (RDGKKVD QYKGKRD) conjugated to keyhole limpet hemocyanin (KLH). The specificity of the antibody was confirmed by Western blot analysis using various recombinant proteins. The antibody was compared with the antibody made by Abcam, which showed similar results of immunohistochemistry and Western blotting. Rabbit antibody was diluted 5,000-fold in $0.05 \mathrm{M}$ carbonate-bicarbonate buffer (pH 9.6) and used to coat 96-well ELISA microplates (Corning Life Science, Amsterdam, Netherlands) by overnight incubation at $4^{\circ} \mathrm{C}$. After a brief wash with PBS containing $0.1 \%$ Tween-20 (PBST), plates were blocked with $5 \%$ nonfat dry milk for one hour at room temperature. Next, blood samples were diluted 10-fold, and incubated in the plates for two hours at room temperature. After washing with PBST, goat anti-TXNDC5 antibody (Abcam), diluted 4,000-fold, was added to the plates and incubated for two hours at room temperature. Following a 
washing step, a 15,000-fold dilution of anti goat IgG alkaline phosphatase-conjugated antibody (Sigma) was added, and plates were incubated for 30 minutes at room temperature. Following another PBST wash, plates were developed by adding alkaline phosphatase yellow (pNPP) liquid substrate for ELISA (Sigma). Absorbance at $405 \mathrm{~nm}$ was measured using a plate reader (Synergy HT, Bio-Tek, Winooski, VT, USA). We repeated the ELISA three times and obtained the similar results.

Sandwich ELISA has low inter-assay and intra-assay variability and provides more accurate results than direct ELISA in which patient sera were coated on the plate and were then detected using the antibody.

\section{ELISA detecting serum levels of anti TXNDC5 antibody}

Levels of anti TXNDC5 antibody were measured in the blood of patients with RA, OA, or AS ( $n=50$ for each disease) as well as healthy controls $(n=50)$. One hundred microLs of SLHRFVLSQAKDEL (0.5 ug/ul), the oligopeptide against TXNDC5, were coated onto 96-well ELISA microplates by overnight incubation at $4{ }^{\circ} \mathrm{C}$. After a brief wash with PBST, plates were blocked with 5\% nonfat dry milk for one hour at room temperature. Serum samples, diluted 20-fold, were added and plates were incubated for two hours at $37^{\circ} \mathrm{C}$. After washing with PBST, a 5,000-fold dilution of anti-human IgG alkaline phosphatase-conjugated antibody (Sigma) was added, and plates were incubated for 30 minutes at room temperature. Following another PBST wash, plates were developed by adding the alkaline phosphatase yellow (pNPP) liquid substrate for ELISA (Sigma). Absorbance at $405 \mathrm{~nm}$ was measured using a plate reader.

\section{Genomic DNA extraction}

Genomic DNA was extracted from peripheral blood leukocytes using the DNA Blood Mini Kit from Qiagen (Hilden, Germany) according to the manufacturer's guidelines. Briefly, $5 \mathrm{ml}$ of blood was mixed with triton lysis buffer (0.32 M sucrose, $1 \%$ Triton X-100, $5 \mathrm{mM} \mathrm{MgCl}_{2}, \mathrm{H}_{2} \mathrm{O}$, $10 \mathrm{mM}$ Tris- $\mathrm{HCl}, \mathrm{pH}$ 7.5). Leukocytes were spun down and washed with $\mathrm{H}_{2} \mathrm{O}$. Pellets were incubated with proteinase $\mathrm{K}$ at $56^{\circ} \mathrm{C}$ and subsequently salted out at $4{ }^{\circ} \mathrm{C}$ using a substrate $\mathrm{NaCl}$ solution. Precipitated proteins were removed by centrifugation. The DNA in the supernatants was precipitated with ethanol, and the resulting DNA pellets were dissolved in $400 \mu \mathrm{l} \mathrm{H}_{2} \mathrm{O}$.

\section{SNPs selection}

Illumina GoldenGate assays were performed to genotype 96 SNPs within or near the TXNDC5 gene in 267 RA patients, 51 AS patients and 160 healthy control individuals from the Shandong area of North China. Tag SNPs, SNPs in untranslational region (UTR) and SNPs either in exons or in close proximity to exons of the gene encoding
TXNDC5 were selected for genotyping. Tag SNPs were selected from HapMap data with a pair-wise $r^{2} \geq 0.8$ and minor allele frequencies (MAF) over $0.05[9,10]$. Coding SNPs, SNPs near exons in $500 \mathrm{bp}$, SNPs in UTR and SNPs near the 5' and 3' ends of the gene were also selected. A total of 156 SNPs were candidates for Illumina's GoldenGate design and were submitted to Illumina for a design score. The Illumina Assay Design Tool (Illumina, San Diego, CA, USA) filtered out SNPs not suitable for the Illumina platform, such as insertions/deletions, tri- and tetra-allelic SNPs, and SNPs that are not uniquely localized. Finally, 96 SNPs with a design score of 1, spanning $0.18 \mathrm{Mb}$ of the chromosome were selected. These SNPs included 5 coding SNPs, 4 SNPs at the 3' UTR, 35 tag SNPs and 53 SNPs in introns or near the 5 ' end. The gene information of these SNPs is shown in Table 1.

\section{Table 1 Single nucleotide polymorphism (SNP)} information

\begin{tabular}{|c|c|c|c|c|c|}
\hline SNP ID & $\begin{array}{c}\text { Chromosome } \\
\text { position }\end{array}$ & Locus & Allele & $\begin{array}{l}\text { Protein } \\
\text { residue }\end{array}$ & \\
\hline rs1044104 & 7881311 & 3' near gene & $\mathrm{C} / \mathrm{T}$ & & \\
\hline rs9505298 & 7881449 & 3 ' near gene & $A / G$ & & \\
\hline rs41302895 & 7881754 & $3^{\prime}$ UTR & $\mathrm{A} / \mathrm{T}$ & & \\
\hline rs1043784 & 7881931 & 3' UTR & $\mathrm{A} / \mathrm{G}$ & & \\
\hline rs7764128 & 7882205 & $3^{\prime}$ UTR & $\mathrm{A} / \mathrm{G}$ & & \\
\hline rs8643 & 7883073 & 3' UTR & $A / G$ & & \\
\hline rs9502656 & 7883386 & synonymous & $\mathrm{T}$ & Asp [D] & \\
\hline rs35264740 & 7883865 & intron & $\mathrm{C} / \mathrm{T}$ & & \\
\hline rs17764309 & 7883916 & intron & $\mathrm{A} / \mathrm{G}$ & & \\
\hline rs17696707 & 7884242 & intron & $\mathrm{A} / \mathrm{G}$ & & \\
\hline rs35871461 & 7884291 & intron & $\mathrm{C} / \mathrm{T}$ & & \\
\hline rs2277105 & 7884652 & synonymous & A & Ala $[\mathrm{A}]$ & tag SNP \\
\hline rs1225936 & 7885184 & intron & $\mathrm{A} / \mathrm{C}$ & & \\
\hline rs1225937 & 7885302 & intron & $\mathrm{C} / \mathrm{T}$ & & \\
\hline rs35794653 & 7885337 & intron & $-/ A$ & & \\
\hline rs9505300 & 7885364 & intron & $\mathrm{C} / \mathrm{T}$ & & \\
\hline rs1225938 & 7886534 & intron & $A / G$ & & \\
\hline rs34342519 & 7886673 & intron & $-/ C$ & & \\
\hline rs11962800 & 7886905 & intron & $\mathrm{A} / \mathrm{G}$ & & \\
\hline rs9505301 & 7887131 & intron & $A / G$ & & \\
\hline rs372578 & 7887223 & intron & $\mathrm{A} / \mathrm{G}$ & & \\
\hline rs7740689 & 7888066 & intron & $A / G$ & & \\
\hline rs89715 & 7888168 & intron & $\mathrm{C} / \mathrm{T}$ & & \\
\hline rs7745225 & 7888251 & intron & $\mathrm{C} / \mathrm{T}$ & & \\
\hline rs378963 & 7888328 & intron & $\mathrm{C} / \mathrm{T}$ & & \\
\hline rs45441296 & 7889033 & missense & A & Met [M] & \\
\hline rs1225944 & 7889088 & intron & $\mathrm{C} / \mathrm{T}$ & & \\
\hline rs34782746 & 7889254 & intron & $\mathrm{C} / \mathrm{T}$ & & \\
\hline rs1225946 & 7889465 & intron & $\mathrm{C} / \mathrm{T}$ & & \\
\hline rs7746818 & 7889466 & intron & $\mathrm{A} / \mathrm{G}$ & & \\
\hline rs34228534 & 7889773 & frame shift & & Gln $[Q]$ & \\
\hline rs1225947 & 7890121 & intron & $\mathrm{G} / \mathrm{T}$ & & \\
\hline
\end{tabular}


Table 1 Single nucleotide polymorphism (SNP) information (Continued)

\begin{tabular}{|c|c|c|c|c|c|}
\hline rs13873 & 7891160 & intron & $\mathrm{G} / \mathrm{T}$ & & $\operatorname{tag}$ SNP \\
\hline rs34963444 & 7891384 & intron & $\mathrm{C} / \mathrm{T}$ & & \\
\hline rs7771314 & 7891403 & intron & $\mathrm{C} / \mathrm{T}$ & & \\
\hline rs9502657 & 7891682 & intron & $\mathrm{A} / \mathrm{C}$ & & \\
\hline rs9502658 & 7891947 & synonymous & $\mathrm{T}$ & Phe $[\mathrm{F}]$ & \\
\hline rs35365768 & 7892037 & intron & $-/ C$ & & \\
\hline rs1225950 & 7892143 & intron & $C / G$ & & \\
\hline rs7749719 & 7894695 & intron & $\mathrm{C} / \mathrm{T}$ & & \\
\hline rs1238994 & 7894794 & intron & $\mathrm{G} / \mathrm{T}$ & & \\
\hline rs35650329 & 7895782 & intron & $-/ G$ & & \\
\hline rs443861 & 7896491 & intron & $\mathrm{A} / \mathrm{G}$ & & tag SNP \\
\hline rs369086 & 7898875 & intron & $\mathrm{A} / \mathrm{G}$ & & $\operatorname{tag}$ SNP \\
\hline rs408014 & 7899394 & intron & $\mathrm{A} / \mathrm{G}$ & & \\
\hline rs368074 & 7899569 & intron & $C / G$ & & \\
\hline rs420970 & 7899651 & intron & $\mathrm{C} / \mathrm{T}$ & & \\
\hline rs1225954 & 7900028 & intron & $\mathrm{A} / \mathrm{G}$ & & \\
\hline rs1225955 & 7900709 & intron & $\mathrm{A} / \mathrm{G}$ & & \\
\hline rs6933089 & 7900856 & intron & $\mathrm{C} / \mathrm{T}$ & & \\
\hline rs13209404 & 7909967 & intron & $\mathrm{C} / \mathrm{T}$ & & \\
\hline rs13210097 & 7911345 & $5^{\prime}$ near gene & $\mathrm{A} / \mathrm{C}$ & & \\
\hline rs9502663 & 7911474 & $5^{\prime}$ near gene & $\mathrm{A} / \mathrm{C}$ & & \\
\hline rs3812162 & 7911702 & $5^{\prime}$ near gene & $\mathrm{A} / \mathrm{C}$ & & $\operatorname{tag}$ SNP \\
\hline rs34066135 & 7911855 & $5^{\prime}$ near gene & $-/ G$ & & \\
\hline rs1632346 & 7913546 & intron & $\mathrm{C} / \mathrm{T}$ & & $\operatorname{tag}$ SNP \\
\hline rs1743634 & 7916207 & intron & $\mathrm{A} / \mathrm{T}$ & & $\operatorname{tag}$ SNP \\
\hline rs9505309 & 7917528 & intron & $\mathrm{G} / \mathrm{T}$ & & $\operatorname{tag}$ SNP \\
\hline rs6922018 & 7918311 & intron & $A / G$ & & $\operatorname{tag}$ SNP \\
\hline rs6923488 & 7918405 & intron & $\mathrm{C} / \mathrm{T}$ & & $\operatorname{tag}$ SNP \\
\hline rs1594467 & 7920361 & intron & $\mathrm{A} / \mathrm{G}$ & & $\operatorname{tag}$ SNP \\
\hline rs419588 & 7920808 & intron & $\mathrm{C} / \mathrm{T}$ & & $\operatorname{tag}$ SNP \\
\hline rs365936 & 7920904 & intron & $\mathrm{A} / \mathrm{C}$ & & $\operatorname{tag}$ SNP \\
\hline rs1237879 & 7932261 & intron & $\mathrm{A} / \mathrm{G}$ & & tag SNP \\
\hline rs627957 & 7936475 & intron & $\mathrm{C} / \mathrm{T}$ & & $\operatorname{tag}$ SNP \\
\hline rs155487 & 7938773 & intron & $\mathrm{A} / \mathrm{G}$ & & $\operatorname{tag}$ SNP \\
\hline rs10484327 & 7942566 & intron & $\mathrm{A} / \mathrm{C}$ & & $\operatorname{tag}$ SNP \\
\hline rs7764884 & 7970540 & intron & $A / G$ & & $\operatorname{tag}$ SNP \\
\hline rs7763447 & 7973380 & intron & $A / G$ & & $\operatorname{tag}$ SNP \\
\hline rs9406071 & 7974705 & intron & $\mathrm{C} / \mathrm{T}$ & & $\operatorname{tag}$ SNP \\
\hline rs6597292 & 7975259 & intron & $\mathrm{G} / \mathrm{T}$ & & $\operatorname{tag}$ SNP \\
\hline rs197119 & 7976745 & intron & $\mathrm{A} / \mathrm{G}$ & & $\operatorname{tag}$ SNP \\
\hline rs6597293 & 7987883 & intron & $C / G$ & & $\operatorname{tag} S N P$ \\
\hline rs11754300 & 7988766 & intron & $\mathrm{C} / \mathrm{T}$ & & $\operatorname{tag}$ SNP \\
\hline rs7744601 & 7988910 & intron & $\mathrm{C} / \mathrm{T}$ & & tag SNP \\
\hline rs2567226 & 7993977 & intron & $A / G$ & & $\operatorname{tag}$ SNP \\
\hline rs12204273 & 8002705 & intron & $\mathrm{A} / \mathrm{G}$ & & $\operatorname{tag}$ SNP \\
\hline rs9392182 & 8009035 & intron & $\mathrm{A} / \mathrm{T}$ & & $\operatorname{tag} S N P$ \\
\hline rs2207720 & 8019197 & intron & $\mathrm{C} / \mathrm{T}$ & & $\operatorname{tag}$ SNP \\
\hline rs9392189 & 8021532 & intron & $A / G$ & & tag SNP \\
\hline rs2815128 & 8023462 & intron & $\mathrm{G} / \mathrm{T}$ & & $\operatorname{tag}$ SNP \\
\hline rs2815142 & 8043546 & intron & $A / G$ & & $\operatorname{tag}$ SNP \\
\hline rs2743992 & 8054722 & intron & $\mathrm{A} / \mathrm{G}$ & & $\operatorname{tag}$ SNP \\
\hline
\end{tabular}

Table 1 Single nucleotide polymorphism (SNP) information (Continued)

\begin{tabular}{llcll}
\hline rs2294436 & 8057688 & intron & $\mathrm{C} / T$ & tag SNP \\
rs2743991 & 8060175 & intron & $\mathrm{A} / \mathrm{G}$ & tag SNP \\
rs9405369 & 8062437 & intron & $\mathrm{A} / \mathrm{T}$ & \\
rs12207627 & 8062532 & intron & $\mathrm{A} / \mathrm{G}$ & \\
rs2743989 & 8064035 & intron & $\mathrm{C} / T$ & \\
rs2815153 & 8064050 & intron & $\mathrm{C} / T$ & \\
rs2815154 & 8064084 & intron & $\mathrm{C} / T$ & \\
rs9328453 & 8065127 & 5' near gene & $\mathrm{A} / \mathrm{G}$ & \\
rs2815155 & 8065230 & 5' near gene & $\mathrm{C} / \mathrm{T}$ & \\
rs12660697 & 8065707 & 5' near gene & $\mathrm{A} / \mathrm{G}$ & \\
rs9392956 & 8065769 & 5' near gene & $\mathrm{C} / \mathrm{T}$ & \\
rs9392957 & 8065781 & 5' near gene & $\mathrm{A} / \mathrm{C}$ & \\
rs9505351 & 8066286 & 5' near gene & $\mathrm{G} / \mathrm{T}$ & \\
\hline
\end{tabular}

\section{Genotyping using microarray}

We performed genotyping using custom-designed Illumina 96-SNP VeraCode microarrays (Illumina). Genotyping was completed by technique service in Dr. Zhang Feng's Laboratory of he Beijing Institute of Genomics. A BeadXpress Reader using Illumina VeraCode GoldenGate Assay Kit was used. A total of 500 ng of sample DNA was used per assay. Genotype clustering and calling were performed using BeadStudio software (Illumina).

\section{Genotyping using Taqman SNP assay}

Four tag SNPs, rs2277105, rs369086, rs443861 and rs11962800, were genotyped using TaqMan SNP genotyping assays in a cohort of 950 patients with RA (693 female) and 900 healthy controls (630 female). RA patients had a mean age of 46.2 years and were from the Shandong area of Northern China. The diagnosis of RA was conducted as described above. Healthy individuals with a mean age of 43.1 years were selected from the same geographical area. Assays were run on a LightCyclerH 480 Instrument (Roche) and evaluated according to the manufacturer's instructions. Reactions were carried out in a total volume of $10 \mu \mathrm{l}$ using the following amplification protocol: denaturation at $95^{\circ} \mathrm{C}$ for 10 minutes, followed by 40 cycles of denaturation at $92^{\circ} \mathrm{C}$ for 15 seconds and finishing with annealing and extension at $60^{\circ} \mathrm{C}$ for 1 minute. The genotype of each sample was determined by measuring allelespecific fluorescence using SDS 2.3 software for allelic discrimination (Roche). Duplicate samples and negative controls were included to check the accuracy of genotyping.

\section{Statistical analysis}

Genotyping SNPs were analyzed for association by comparison of the MAF in cases and controls. Associations of SNPs with RA and AS were evaluated using odds ratios 
(OR) with 95\% confidence intervals (CI). Fisher's exact test was used for comparison between categorical variables. $P$-values less than 0.05 were considered statistically significant. After genotyping, SNP markers were evaluated for significant deviation from Hardy-Weinberg equilibrium. Calculations were performed using SHEsis and Haploview, two powerful web-based platforms for analyses of linkage disequilibrium, haplotype construction and genetic association at polymorphism loci $[11,12]$.

\section{Results}

\section{TXNDC5 expression in the synovial membranes of RA} patients

Immunohistochemistry analysis revealed significant TXCND5 expression in the thick lining layer and in many of the fibroblast-like cells of synovial membranes from RA patients $(n=10)$. Although detectable in the thin lining layer and some endothelial cells of small blood vessels, expression was very weak in the synovial membranes of OA patients $(n=10)$. In AS patients $(n=$ $10)$, TXNDC5 expression was relatively low in synovial membranes and was mainly limited in endothelial cells of small blood vessels. These observations were confirmed by immunofluorescent labeling. Results are shown in Figure 1A. SimplePC (Hamamatsu Photonics, Sewickley, PA, USA), software designed to measure the signal density of the expression in a semi-quantitative manner, detected significantly higher levels of TXNDC5 in synovial tissues from RA patients compared to OA and AS patients (Figure 1B).

Western blots revealed a protein with a molecular weight of $50 \mathrm{kDa}$. in each of the synovial tissues analyzed. Using GADPH as a reference, significantly increased TXNDC5 expression was detected in the synovial membranes of RA patients $(n=10)$, relative to the samples from OA $(n=10)$ and AS $(n=10)$ patients. These results were consistently observed in all of the synovial membranes examined (Figures 2A, B).

Transcription of TXNDC5 was quantified using realtime PCR. Similar to the Western blotting and immunolabeling results, all RA samples $(n=10)$ exhibited a higher degree of TXNDC5 mRNA expression compared to the OA $(n=10)$ and AS $(n=10)$ samples (Figure $2 \mathrm{C})$. TXNDC5 was expressed at a low level in all OA samples.

\section{TXNDC5 levels in blood samples from RA patients}

A sandwich ELISA was used to measure levels of TXNDC5 in the blood of RA patients with chronic inflammation. Levels of TXNDC5 were significantly increased in samples from RA patients compared to samples from OA, AS and SLE patients. Serum TXNDC5 expression in RA patients was also significantly elevated compared to healthy controls (Figure 3A). An ELISA was used to measure serum anti-TXNDC5 antibody levels of the patients. These were not significantly different from serum levels from RA, OA, and AS patients and healthy controls (Figure 3B).

\section{Genotyping of SNPs located in TXNDC5}

We genotyped 96 SNPs across the TXNDC5 gene from 267 Han Chinese patients with RA, 51 patients and 160 control individuals. All SNPs yielded genotype data, and the study sample success rate was $99.1 \%$. Differences in allele frequencies and genotype frequencies between cases and controls were compared. Overall, nine SNPs (rs9505298, rs41302895, rs1225936, rs1225938, rs372578, rs443861, rs408014, rs9392189 and rs2743992) were found to be significantly associated with RA $(P<0.05)$. A total of 16 SNPs (rs1044104, rs1225937, rs1225938, rs372578, rs89715, rs378963, rs1225944, rs1225947, rs1238994, rs369086, rs408014, rs368074, rs1225954, rs1225955, rs13209404 and rs3812162) were found to be significantly associated with AS $(P<0.05)$. Among the genotyped SNPs, three SNPs (rs1225938, rs372578 and rs408014) had significant association with both RA and AS. All SNPs retained in the analysis were in HardyWeinberg equilibrium $(P>0.05)$ in the overall samples. The allele and genotype frequencies of the associated SNPs between cases and controls are shown in Tables 2 and 3. Other SNPs of the TXNDC5 gene polymorphisms did not disclose significant differences in allelic frequencies and genotype frequencies between the RA patients and controls or between AS patients and controls.

Linkage disequilibrium (LD) analysis was performed within the tested SNPs. Pairwise D' values between all SNPs were calculated to determine the extent of LD. LD analysis defined eight blocks in TXNDC5 within the RA population. Rs372578, rs408014 and rs2743992, which showed strong association with RA, were in Blocks 3, 4 and 8 , respectively. LD analysis defined 10 blocks in TXNDC5 within the studied AS population. Block 2 contained rs372578, rs89715, ra378963 and rs1225944, while Block 3 contained rs1238994, rs369086, rs408014 rs368074, rs1225954, rs1225955, rs13209404 and rs3812162, SNPs that showed strong association within AS patients. These results are shown in Figure 4A, B.

In the RA population, haplotype analysis defined 27 haplotypes (frequency > 1\%) in the TXNDC5 gene by LD. Haplotype AA (frequency 79.3\%) in Block 2, haplotype GAAG (frequency 56.4\%) in Block 3, haplotypes GAGGGGA and AGCAAAC (frequencies 56.6\% and $23.1 \%$, respectively) in Block 4 and haplotype AG (frequency $79.3 \%$ ) in Block 8 provide significant evidence to be associated with RA risk $(P=0.0446,0.0125,0.0112,0.0081$ and 0.0336 , respectively). Haplotype analysis defined 40 haplotypes (frequency $>1 \%$ ) within the RA cohort by LD in the control population. Haplotypes AAAGAAG and GAAAGGA (frequencies $44.1 \%$ and $33.3 \%$, respectively) in 

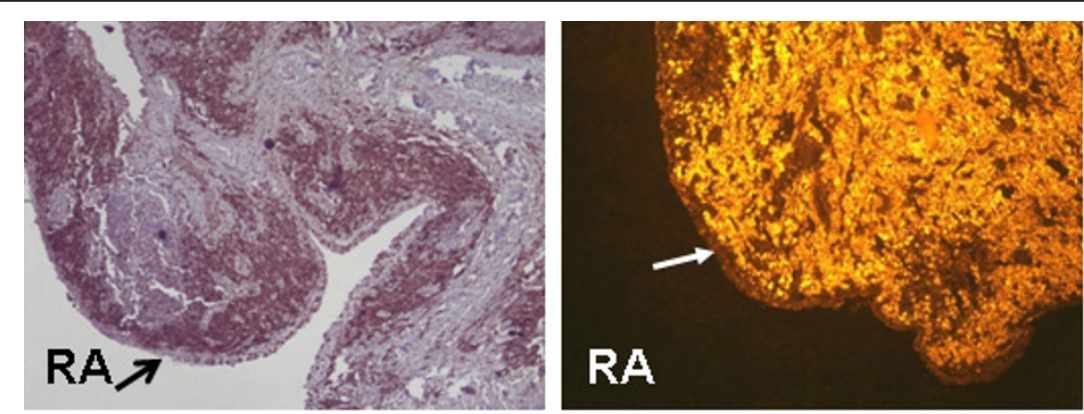

A
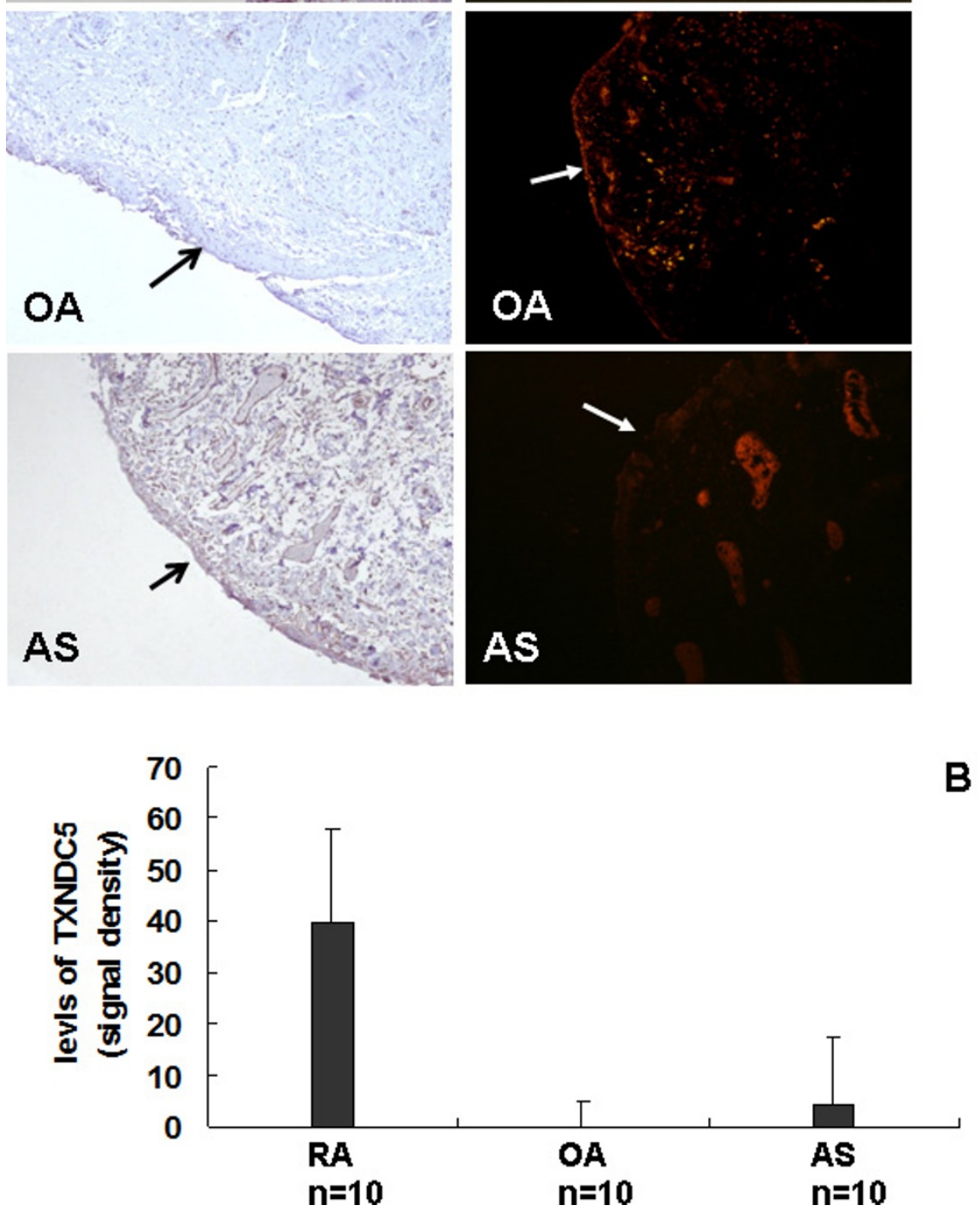

Figure 1 Immunodetection of TXNDC5 in synovial membranes from patients with RA, OA and AS. (A) Immunolocalization of TXNDC5 in synovial membranes. The left lane indicates results of immunohistochemistry, and the right lane indicates results of immunofluorescent labeling. Original magnification: 100x. Arrows indicate the upper layer of synovial membranes. (B) Semi-quantitative analysis of immunofluorescent signals of TXNDC5. TXNDC5 had significantly higher expression in the synovial tissue of RA patients compared to the synovial tissues of OA and AS patients. AS, ankylosing spondylitis; OA, osteoarthritis; RA, rheumatoid arthritis.

Block 2, haplotypes AGGAGGGGA and CGAGCAAAC (frequencies $48.9 \%$ and $29.3 \%$, respectively) in Block 3, haplotype GG (frequency 56.9) in Block 4, and haplotype AGA (frequency 4\%) in Block 5 provided significant evidence to be associated with AS risk $(P=0.0198,0.0043,0.0044$, $0.0018,0.0187$ and 0.0053 , respectively). The haplotype frequencies in a case-control cohort of patients with RA and AS are shown in Tables 4 and 5. The raw microarray data 


\section{A}
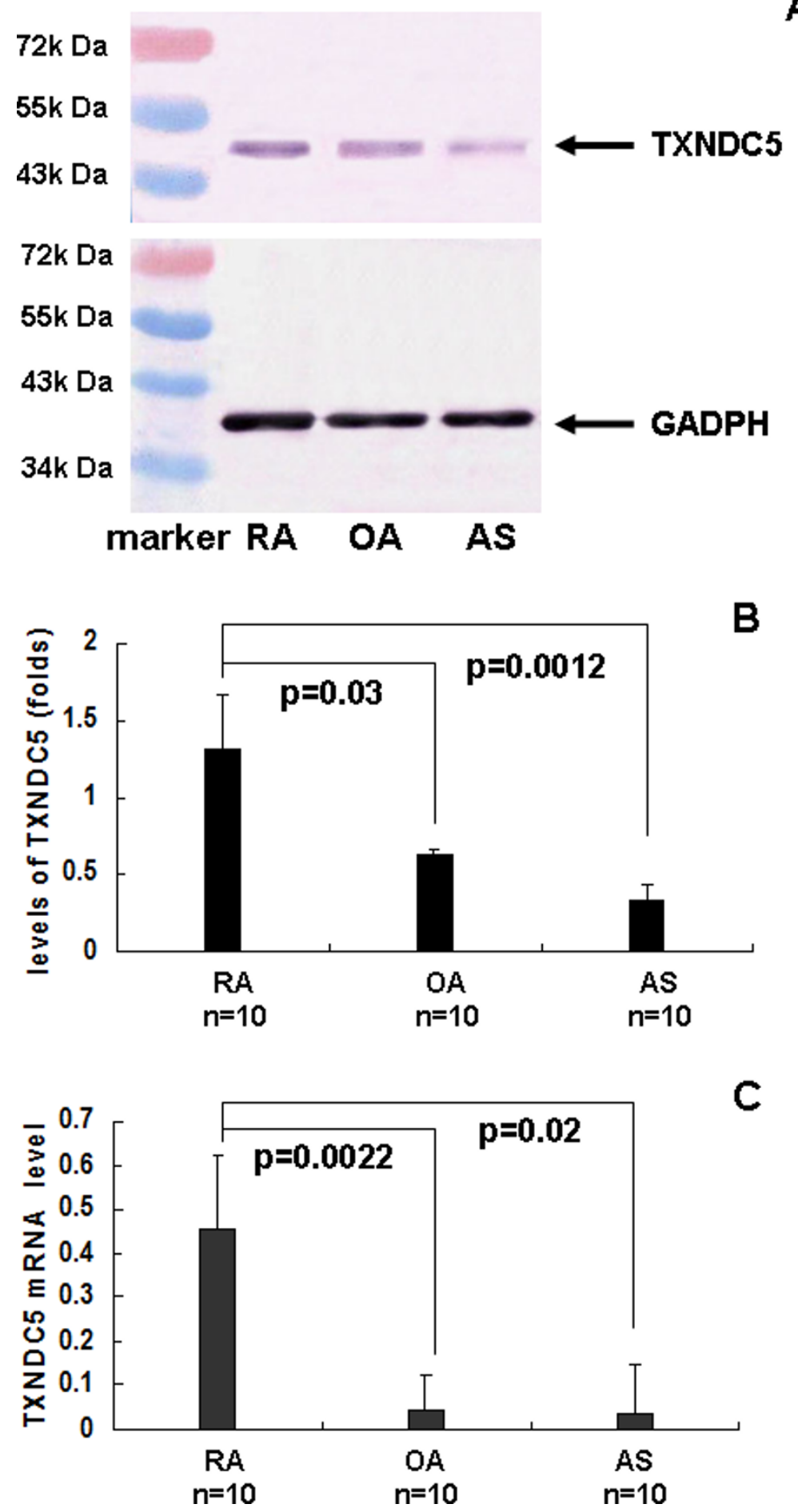

Figure 2 Quantitative analysis of TXNDC5 expression. (A) TXNDC5 at molecular weight of $50 \mathrm{kDa}$ was detected in synovial tissues of RA, OA and AS patients using Western blot analysis. Sample loading was normalized using GADPH at molecular weight of 37 kDa. (B) TXNDC5

expression was semi-quantitatively analyzed by normalizing the signal density of TXNDC5 to that of GADPH. (C) TXNDC5 mRNA expression was measured in synovial tissues using real time PCR. The expression was normalized to that of $\beta$-actin. TXNDC5 had significantly higher expression in the synovial tissue of RA patients compared to the synovial tissues of OA and AS patients. AS, ankylosing spondylitis; OA, osteoarthritis; RA, rheumatoid arthritis. 

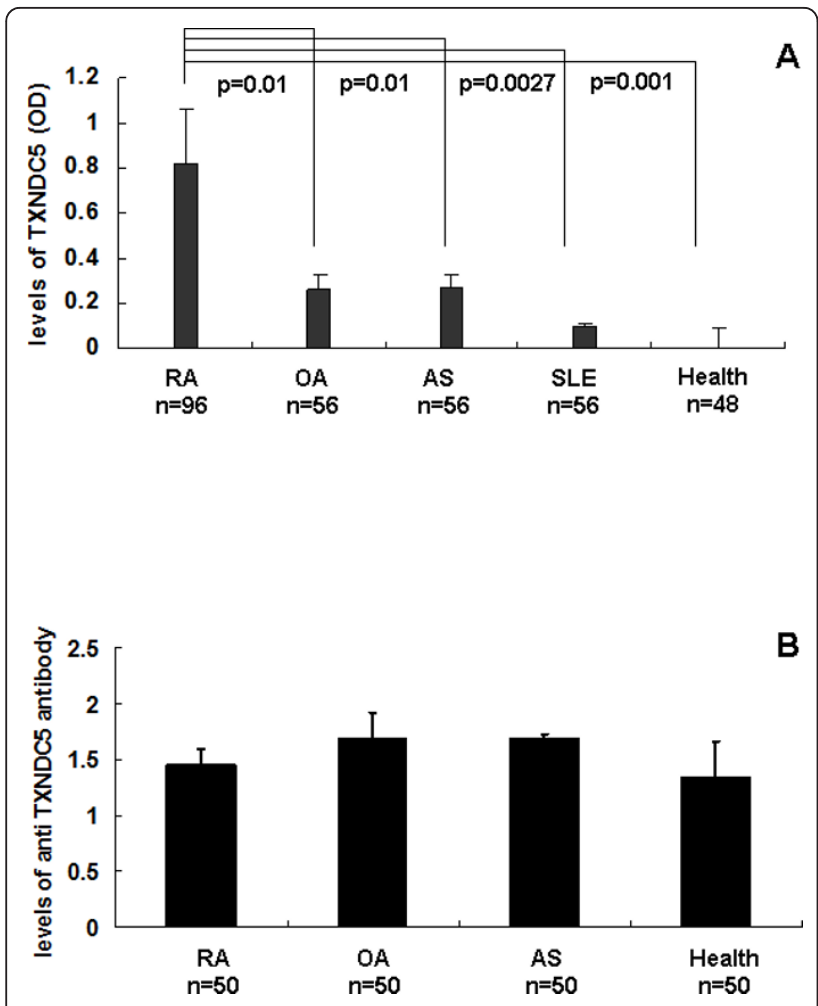

Figure 3 Serum levels of TXNDC5 and anti-TXNDC5 antibody in patients with arthritic diseases and healthy controls. TXNDC5 levels are represented by OD values of absorbance at $405 \mathrm{~nm}$ and are expressed as the mean \pm standard error of the mean. (A) A sandwich ELISA detected increased level of TXNDC5 in blood samples from RA patients compared to samples from OA, AS and SLE patients, as well as from healthy controls. (B) An ELISA indicated that levels of antiTXNDC5 antibodies were not significantly different among blood samples from RA, OA and AS patients and the healthy controls. AS, ankylosing spondylitis; $\mathrm{OA}$, osteoarthritis; RA, rheumatoid arthritis.

were available as an Additional file 2 to perform association, LD and haplotype analysis.

We performed additional genotyping for four SNPs (rs2277105, rs369086, rs443861 and rs11962800) in an independent case-control study using the TaqMan method. The study was conducted within 951 patients with RA and 898 healthy controls. Allelic frequencies and gene frequencies of the four tag SNPs did not deviate from Hardy-Weinberg equilibrium in both case and the controls. Allelic frequency of the tag SNPs was compared between RA patients and controls. Among the polymorphisms identified, the allele frequency and gene frequency for tag SNP rs443861 demonstrated statistically significant evidence for association with RA $(P=0.008320$, and 0.010110 . This SNP was also determined to have significant association with RA by Illumina 96-SNP VeraCode microarray. The tag SNPs of rs2277105, rs369086 and rs11962800 did not disclose significant differences in allelic frequencies and gene frequencies between RA patients and controls (Table 6).

\section{Discussion}

In the present study, TXNDC5 expression was quantitatively assessed both at the transcriptional level and translational level. In comparison to synovial tissue samples from OA and AS patients, TXNDC5 expression was significantly increased in the synovial tissues of RA patients as determined by immunohistochemistry and Western blotting. Real time PCR also detected increased TXNDC5 mRNA levels in the synovial membranes of RA patients. Furthermore, sandwich ELISA detected increased expression of TXNDC5 in both the synovial fluid and blood of RA patients [6]. Taken together, these results confirm the increased expression of TXNDC5 in the synovium and blood of RA patients. In the present study, we did not detect increased levels of autoantibodies directed against TXNDC5 in the blood of RA patients, indicating that the over-expression of TXNDC5 does not directly cause an autoimmune response as an autoantigen like some citrullinated proteins [13]. We processed Western blotting with protein extracted from the whole synovial tissue. The immunohistochemistry focuses on the expression of TXNDC5 in the lining area and the deep lining area of the synovial membrane. Immunofluorescent immunocytochemistry semi-quantified the expression level in one tissue region rather than the whole tissue. In addition, synovial tissues of RA and AS have significantly increased angiogenesis in which endothelial cells of blood vessels have strong expression of TXNDC5. Thus, it is possible the result of semi-quantification of immunofluorescent immunocytochemistry is a little different from the result of Western blotting.

TXNDC5 expression is up-regulated by hypoxia and has a protective effect on endothelial cells by inducing folding and chaperone activity in hypoxia-induced anti-apoptotic molecules $[1,2]$. RA is thought to decrease the oxygen supply, leading to synovial hypoxia and hypoperfusion $[7,8]$. Using co-immunoprecipitation followed by mass spectrometry, Charlton et al. found that TXNDC5 interacts with the N-terminal residues of AdipoR1. Further, transient knockdown of TXNDC5 in HeLa cells increased the levels of AdipoR1 and AdipoR2, which correlated with the increased adiponectin-stimulated phosphorylation of AMPK. However, adiponectin-stimulated phosphorylation of p38MAPK was reduced following TXNDC5 knockdown [4]. Recent reports indicate that AdipoR1 and AdipoR2 mediate the insulin-sensitizing adipokine adiponectin. RA is associated with the increased production of adipokines, cytokine-like mediators that are produced mainly in adipose tissue and synovial cells [14]. Frommer et al. demonstrated that adiponectin was present in inflamed synovium at sites of cartilage invasion in lymphocyte infiltrates and in perivascular areas. Adiponectin stimulates synovial fibroblasts to secrete chemokines, proinflammatory cytokines, prostaglandin synthases, growth factors and factors 
Table 2 Allele and genotype frequencies in a case-control cohort of patients with RA

\begin{tabular}{|c|c|c|c|c|c|}
\hline dbSNP identity & $\begin{array}{c}\text { Allele/ } \\
\text { Genotype }\end{array}$ & $\begin{array}{c}\text { Numbers of patients } \\
\text { with RA (\%) }\end{array}$ & Numbers of controls (\%) & Fisher's $P$-value & Odds ratio $(95 \% \mathrm{Cl})$ \\
\hline \multirow[t]{5}{*}{ rs9505298 } & A & $75(0.144)$ & $10(0.032)$ & $1.83 \mathrm{E}-07$ & 5.157303 (2.624041 to 10.136190$)$ \\
\hline & G & $445(0.856)$ & $306(0.968)$ & & 5.157303 (2.624041 to 10.136190$)$ \\
\hline & AA & $1(0.004)$ & $0(0.000)$ & $3.13 \mathrm{E}-07$ & \\
\hline & $A G$ & $73(0.281)$ & $10(0.063)$ & & \\
\hline & GG & $186(0.715)$ & $148(0.937)$ & & \\
\hline \multirow[t]{5}{*}{ rs41302895 } & A & $64(0.120)$ & $9(0.028)$ & $3.32 \mathrm{E}-06$ & 4.725546 (2.317854 to 9.634252$)$ \\
\hline & $\mathrm{T}$ & $468(0.880)$ & $311(0.972)$ & & 4.725546 (2.317854 to 9.634252$)$ \\
\hline & AA & $1(0.004)$ & $0(0.000)$ & $9.11 \mathrm{E}-06$ & \\
\hline & AT & $62(0.233)$ & $9(0.056)$ & & \\
\hline & $\pi$ & $203(0.763)$ & $151(0.944)$ & & \\
\hline \multirow[t]{4}{*}{ rs1225936 } & A & $24(0.045)$ & $2(0.006)$ & 0.001438 & 7.494071 (1.759029 to 31.927328$)$ \\
\hline & C & $506(0.955)$ & $316(0.994)$ & & 7.494071 (1.759029 to 31.927328$)$ \\
\hline & $A C$ & $24(0.091)$ & $2(0.013)$ & 0.001201 & 7.817427 (1.821928 to 33.542572$)$ \\
\hline & CC & $241(0.909)$ & $157(0.987)$ & & 7.817427 (1.821928 to 33.542572$)$ \\
\hline \multirow[t]{5}{*}{ rs1225938 } & A & $270(0.509)$ & $190(0.594)$ & 0.016879 & 0.710526 (0.536647 to 0.940745$)$ \\
\hline & G & $260(0.491)$ & $130(0.406)$ & & 0.710526 (0.536647 to 0.940745$)$ \\
\hline & AA & $53(0.200)$ & $52(0.325)$ & 0.013717 & \\
\hline & $A G$ & $164(0.619)$ & $86(0.537)$ & & \\
\hline & GG & $48(0.181)$ & $22(0.138)$ & & \\
\hline \multirow[t]{5}{*}{ rs372578 } & A & $224(0.424)$ & $109(0.341)$ & 0.015688 & 1.426364 (1.068889 to 1.903392$)$ \\
\hline & G & $304(0.576)$ & $211(0.659)$ & & 1.426364 (1.068889 to 1.903392$)$ \\
\hline & AA & $45(0.170)$ & $21(0.131)$ & 0.029497 & \\
\hline & $A G$ & $134(0.508)$ & $67(0.419)$ & & \\
\hline & GG & $85(0.322)$ & $72(0.450)$ & & \\
\hline \multirow[t]{5}{*}{ rs443861* } & A & $117(0.221)$ & $48(0.150)$ & 0.011538 & 1.605327 (1.109766 to 2.322179$)$ \\
\hline & G & $413(0.779)$ & $272(0.850)$ & & 1.605327 (1.109766 to 2.322179$)$ \\
\hline & AA & $6(0.023)$ & $3(0.019)$ & 0.016509 & \\
\hline & $A G$ & $105(0.396)$ & $42(0.263)$ & & \\
\hline & GG & $154(0.581)$ & $115(0.719)$ & & \\
\hline \multirow[t]{5}{*}{ rs408014 } & A & $303(0.574)$ & $211(0.659)$ & 0.013531 & 0.695671 (0.521353 to 0.928274$)$ \\
\hline & G & $225(0.426)$ & $109(0.341)$ & & 0.695671 (0.521353 to 0.928274$)$ \\
\hline & $\mathrm{AA}$ & $86(0.326)$ & $72(0.450)$ & 0.03402 & \\
\hline & $A G$ & $131(0.496)$ & $67(0.419)$ & & \\
\hline & GG & $47(0.178)$ & $21(0.131)$ & & \\
\hline \multirow[t]{5}{*}{ rs9392189* } & A & $116(0.221)$ & $103(0.322)$ & 0.001239 & 0.598991 (0.438317 to 0.818563$)$ \\
\hline & G & $408(0.779)$ & $217(0.678)$ & & 0.598991 (0.438317 to 0.818563 ) \\
\hline & AA & $16(0.061)$ & $18(0.113)$ & 0.007146 & \\
\hline & $A G$ & $84(0.321)$ & $67(0.419)$ & & \\
\hline & GG & $162(0.618)$ & $75(0.469)$ & & \\
\hline \multirow[t]{5}{*}{ rs2743992* } & A & $230(0.437)$ & $163(0.509)$ & 0.041455 & 0.748425 (0.566338 to 0.989055$)$ \\
\hline & G & $296(0.563)$ & $157(0.491)$ & & 0.748425 (0.566338 to 0.989055$)$ \\
\hline & AA & $43(0.163)$ & $44(0.275)$ & 0.022536 & \\
\hline & $A G$ & $144(0.548)$ & $75(0.469)$ & & \\
\hline & GG & $76(0.289)$ & $41(0.256)$ & & \\
\hline
\end{tabular}

160 controls and 266 cases were observed; *represents tag SNP.

95\% Cl, 95\% confidence interval; RA, rheumatoid arthritis; SNP, single nucleotide polymorphism.

for bone metabolism and matrix remodelling. This adiponectin-mediated effect was p38 MAPK and protein kinase $\mathrm{C}$ dependent. Adiponectin promotes inflammation through cytokine and chemokine production that attracts inflammatory and pro-destructive cells to the synovium, which, in turn promotes matrix destruction at sites of cartilage invasion [15]. Choi et al. reported that adiponectin might contribute to synovitis and joint destruction in RA 
Table 3 Allele and genotype frequencies in a case-control cohort of patients with AS

\begin{tabular}{|c|c|c|c|c|c|}
\hline dbSNP identity & Allele/Genotype & $\begin{array}{c}\text { Numbers of patients } \\
\text { with RA (\%) }\end{array}$ & Numbers of controls (\%) & Fisher's $P$-value & Odds Ratio $(95 \% \mathrm{Cl})$ \\
\hline \multirow[t]{5}{*}{ rs1044104 } & A & $49(0.480)$ & $103(0.322)$ & 0.0037 & 1.947793 (.237327 to 3.066204$)$ \\
\hline & G & $53(0.520)$ & $217(0.678)$ & & $1.947793(.237327$ to 3.066204$)$ \\
\hline & AA & $13(0.255)$ & $20(0.125)$ & 0.022555 & \\
\hline & $A G$ & $23(0.451)$ & $63(0.394)$ & & \\
\hline & GG & $15(0.294)$ & $77(0.481)$ & & \\
\hline \multirow[t]{5}{*}{ rs1225937 } & A & $67(0.657)$ & $252(0.787)$ & 0.007503 & 0.516553 ( 0.316863 to 0.842090$)$ \\
\hline & G & $35(0.343)$ & $68(0.212)$ & & 0.516553 (0.316863 to 0.842090$)$ \\
\hline & AA & $22(0.431)$ & $99(0.619)$ & 0.027945 & \\
\hline & $A G$ & $23(0.451)$ & $54(0.338)$ & & \\
\hline & GG & $6(0.118)$ & $7(0.044)$ & & \\
\hline \multirow[t]{5}{*}{ rs1225938 } & A & $46(0.451)$ & $190(0.594)$ & 0.011468 & 0.562030 ( 0.358612 to 0.880834$)$ \\
\hline & G & $56(0.549)$ & $130(0.406)$ & & 0.562030 ( 0.358612 to 0.880834$)$ \\
\hline & AA & $11(0.216)$ & $52(0.325)$ & 0.013973 & \\
\hline & $A G$ & $24(0.471)$ & $86(0.537)$ & & \\
\hline & GG & $16(0.314)$ & $22(0.138)$ & & \\
\hline \multirow[t]{5}{*}{ rs372578 } & A & $50(0.490)$ & $109(0.341)$ & 0.006659 & $1.861327(1.184652$ to 2.924518$)$ \\
\hline & G & $52(0.510)$ & $211(0.659)$ & & $1.861327(1.184652$ to 2.924518$)$ \\
\hline & AA & $14(0.275)$ & $21(0.131)$ & 0.029107 & \\
\hline & $A G$ & $22(0.431)$ & $67(0.419)$ & & \\
\hline & GG & $15(0.294)$ & $72(0.450)$ & & \\
\hline \multirow[t]{5}{*}{ rs89715 } & A & $52(0.510)$ & $212(0.662)$ & 0.005544 & 0.529811 ( 0.337112 to 0.832662$)$ \\
\hline & G & $50(0.490)$ & $108(0.338)$ & & 0.529811 ( 0.337112 to 0.832662$)$ \\
\hline & AA & $15(0.294)$ & $73(0.456)$ & 0.026647 & \\
\hline & $A G$ & $22(0.431)$ & $66(0.412)$ & & \\
\hline & GG & $14(0.275)$ & $21(0.131)$ & & \\
\hline \multirow[t]{5}{*}{ rs378963 } & $A$ & $63(0.643)$ & $253(0.791)$ & 0.002897 & 0.476680 (0.291090 to 0.780596$)$ \\
\hline & G & $35(0.357)$ & $67(0.209)$ & & 0.476680 (0.291090 to 0.780596$)$ \\
\hline & AA & $20(0.408)$ & $100(0.625)$ & 0.012477 & \\
\hline & $A G$ & $23(0.469)$ & $53(0.331)$ & & \\
\hline & GG & $6(0.122)$ & $7(0.044)$ & & \\
\hline \multirow[t]{5}{*}{ rs1225944 } & A & $35(0.357)$ & $66(0.206)$ & 0.002276 & $2.138047(1.304553$ to 3.504071$)$ \\
\hline & G & $63(0.643)$ & $254(0.794)$ & & 2.138047 (1.304553 to 3.504071$)$ \\
\hline & AA & $6(0.122)$ & $7(0.044)$ & 0.010406 & \\
\hline & $A G$ & $23(0.469)$ & $52(0.325)$ & & \\
\hline & GG & $20(0.408)$ & $101(0.631)$ & & \\
\hline \multirow[t]{5}{*}{ rs1225947 } & A & $51(0.500)$ & $108(0.338)$ & 0.0032 & 1.962963 (1.249087 to 3.084832$)$ \\
\hline & C & $51(0.500)$ & $212(0.662)$ & & 1.962963 (1.249087 to 3.084832$)$ \\
\hline & AA & $13(0.255)$ & $21(0.131)$ & 0.017854 & \\
\hline & $A C$ & $25(0.490)$ & $66(0.412)$ & & \\
\hline & $\mathrm{CC}$ & $13(0.255)$ & $73(0.456)$ & & \\
\hline \multirow[t]{5}{*}{ rs1238994 } & A & $52(0.510)$ & $210(0.656)$ & 0.007966 & 0.544762 (0.346807 to 0.855709$)$ \\
\hline & C & $50(0.490)$ & $110(0.344)$ & & 0.544762 (0.346807 to 0.855709$)$ \\
\hline & AA & $15(0.294)$ & $71(0.444)$ & 0.031615 & \\
\hline & $A C$ & $22(0.431)$ & $68(0.425)$ & & \\
\hline & $\mathrm{CC}$ & $14(0.275)$ & $21(0.131)$ & & \\
\hline \multirow[t]{5}{*}{ rs369086* } & A & $35(0.343)$ & $66(0.208)$ & 0.005322 & $1.994573(1.221370$ to 3.257261$)$ \\
\hline & G & $67(0.657)$ & $252(0.792)$ & & $1.994573(1.221370$ to 3.257261$)$ \\
\hline & AA & $6(0.118)$ & $7(0.044)$ & 0.022037 & \\
\hline & $A G$ & $23(0.451)$ & $52(0.327)$ & & \\
\hline & GG & $22(0.431)$ & $100(0.629)$ & & \\
\hline rs408014 & $A$ & $50(0.500)$ & $211(0.659)$ & 0.004146 & 0.516588 ( 0.327716 to 0.814312$)$ \\
\hline
\end{tabular}


Table 3 Allele and genotype frequencies in a case-control cohort of patients with AS (Continued)

\begin{tabular}{|c|c|c|c|c|c|}
\hline & G & $50(0.500)$ & $109(0.341)$ & & 0.516588 (0.327716 to 0.814312$)$ \\
\hline & AA & $14(0.280)$ & $72(0.450)$ & 0.020441 & \\
\hline & $A G$ & $22(0.440)$ & $67(0.419)$ & & \\
\hline & GG & $14(0.280)$ & $21(0.131)$ & & \\
\hline \multirow[t]{5}{*}{ rs368074 } & C & $50(0.500)$ & $109(0.341)$ & 0.004146 & $1.935780(1.228031$ to 3.051425$)$ \\
\hline & G & $50(0.500)$ & $211(0.659)$ & & $1.935780(1.228031$ to 3.051425$)$ \\
\hline & CC & $14(0.280)$ & $21(0.131)$ & 0.020441 & \\
\hline & CG & $22(0.440)$ & $67(0.419)$ & & \\
\hline & GG & $14(0.280)$ & $72(0.450)$ & & \\
\hline \multirow[t]{5}{*}{ rs1225954 } & A & $50(0.500)$ & $109(0.341)$ & 0.004146 & $1.935780(1.228031$ to 3.051425$)$ \\
\hline & G & $50(0.500)$ & $11(0.659)$ & & $1.935780(1.228031$ to 3.051425$)$ \\
\hline & $\mathrm{AA}$ & $14(0.280)$ & $21(0.131)$ & 0.020441 & \\
\hline & $A G$ & $22(0.440)$ & $67(0.419)$ & & \\
\hline & GG & $14(0.280)$ & $72(0.450)$ & & \\
\hline \multirow[t]{5}{*}{ rs1225955 } & A & $50(0.500)$ & $108(0.338)$ & 0.003427 & 1.962963 (1.244946 to 3.095092$)$ \\
\hline & G & $50(0.500)$ & $212(0.662)$ & & 1.962963 (1.244946 to 3.095092$)$ \\
\hline & AA & $14(0.280)$ & $21(0.131)$ & 0.018534 & \\
\hline & $A G$ & $22(0.440)$ & $66(0.412)$ & & \\
\hline & GG & $14(0.280)$ & $73(0.456)$ & & \\
\hline \multirow[t]{5}{*}{ rs13209404 } & A & $30(0.300)$ & $59(0.184)$ & 0.013556 & 1.895884 (1.135508 to 3.165434$)$ \\
\hline & G & $70(0.700)$ & $261(0.816)$ & & 1.895884 (1.135508 to 3.165434$)$ \\
\hline & AA & $4(0.080)$ & $7(0.044)$ & 0.043599 & \\
\hline & $A G$ & $22(0.440)$ & $45(0.281)$ & & \\
\hline & GG & $24(0.480)$ & $108(0.675)$ & & \\
\hline \multirow[t]{5}{*}{ rs3812162* } & A & $70(0.700)$ & $268(0.838)$ & 0.002475 & $0.452736(0.268969$ to 0.762060$)$ \\
\hline & $C$ & $30(0.300)$ & $52(0.163)$ & & $0.452736(0.268969$ to 0.762060$)$ \\
\hline & $\mathrm{AA}$ & $23(0.460)$ & $114(0.713)$ & 0.004576 & \\
\hline & $A C$ & $24(0.480)$ & $40(0.250)$ & & \\
\hline & CC & $3(0.060)$ & $6(0.037)$ & & \\
\hline
\end{tabular}

160 controls \& 266 cases were observed; *represents tag SNP. 95\% Cl, 95\% confidence interval; AS, ankylosing spondylitis; SNP, single nucleotide polymorphism.

by stimulating vascular endothelial growth factor, matrix metalloproteinase-1, and matrix metalloproteinase-13 expression in fibroblast-like synoviocytes [16]. Additionally, Tian $e t$ al. also reported that increased PDI activity in myocardial endothelial cells in mice stimulates angiogenesis under hypoxia condition [17]. These results support the possibility that the increase of TXNDC5 expression in the synovial tissues of RA patients stimulates the synovial ocular pannus, pro-inflammation and bone degradation. However, the detailed mechanism requires further investigation.

TXNDC5 is a newly identified member of this protein family. TXNDC5 has been genetically mapped to chromosome $6 \mathrm{p} 24.3$. The gene encoding TXNDC5 is approximately $845.2 \mathrm{k} \mathrm{bp}$, and it is divided into 13 exons. The present study genotyped 96 SNPs flanking the TXNDC5 gene through Illumina GoldenGate assays. Further, the study also genotyped four tag SNPs in the TXNDC5 gene using the Taqman method to confirm association to RA in a large number of samples. Both methods revealed the strong association of rs443861 with RA, indicating a genetic effect of TXNDC5 on RA risk. Although the genetic data of the present study indicated the possible association of TXNDC5 to RA, not enough data support the idea that the increased expression was caused by a genetic mechanism. The increased expression of TXNDC5 could be induced by hypoxia in RA rather than genetic variation of the gene. To determine whether variations in the TXNDC5 gene contributed to the risk of developing nonsegmental vitiligo (NSV), Jeong et al. conducted a case-control association study within a Korean population. They genotyped seven SNPs and found that three exonic SNPs (rs1043784, rs7764128 and rs8643) were statistically associated with NSV. The haplotypes AGG and GAA, consisting of rs1043784, rs7764128 and rs8643, demonstrated a significant association with NSV [18]. Lin et al. reported that SNP rs13873 and haplotypes rs1225934 to rs13873 of BMP6-TXNDC5 genes were significantly associated with schizophrenia [19]. These reports indicate that TXNDC5 plays a role in the pathogenesis of other diseases. Our results demonstrated that 

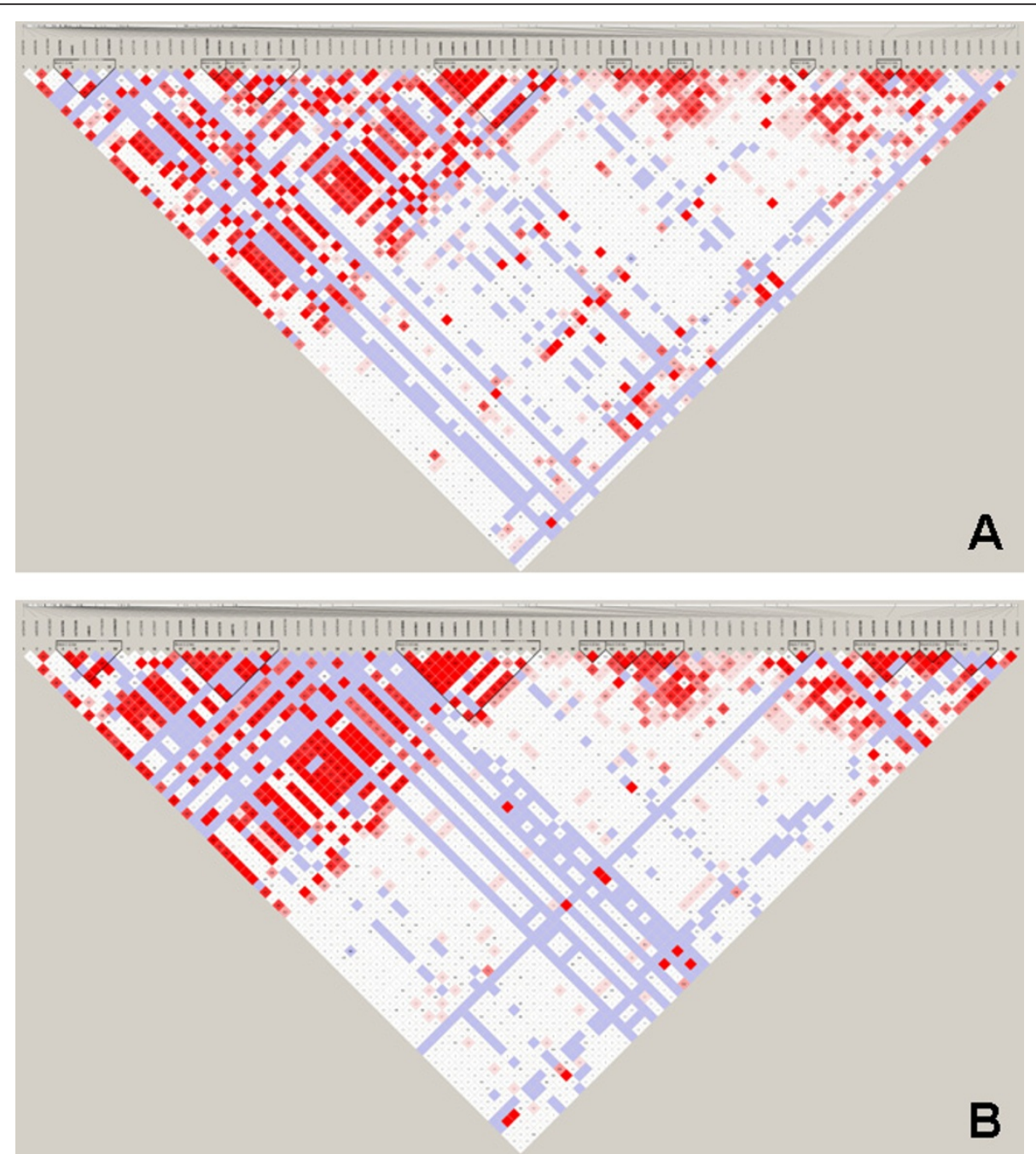

Figure 4 LD plot of the 96 genotyped SNPs in the TXNDC5 gene. (A) Linkage disequilibrium in the RA group. (B) Linkage disequilibrium in the AS group. Red areas representing higher levels of LD. Blue areas represent LD comparisons with low confidence of estimation. Dark triangles represent haplotype blocks. Numbers in squares are D’ values. AS, ankylosing spondylitis; RA, rheumatoid arthritis; SNP, single nucleotide polymorphism.

Table 4 Haplotype frequencies in a case-control cohort of patients with rheumatoid arthritis

\begin{tabular}{|c|c|c|c|c|}
\hline Haplotype & Freq. & Case, Control Ratio Counts & Case, Control Frequencies & $P$-Value \\
\hline \multicolumn{5}{|l|}{ Block 1} \\
\hline AGG & 0.827 & 426.9: 101.1, 273.0: 45.0 & $0.808,0.858$ & 0.0625 \\
\hline GAA & 0.145 & 81.0: 447.0, 42.0: 276.0 & $0.153,0.132$ & 0.3939 \\
\hline AAG & 0.012 & 7.8: 520.2, 2.0: 316.0 & $0.015,0.006$ & 0.2649 \\
\hline \multicolumn{5}{|l|}{ Block 2} \\
\hline $\mathrm{AA}$ & 0.814 & 418.9: 109.1, 269.9: 48.1 & $0.793,0.849$ & 0.0446 \\
\hline GG & 0.155 & 87.9: 440.1, 42.9: 275.1 & $0.166,0.135$ & 0.2187 \\
\hline$A G$ & 0.024 & 15.1: 512.9, 5.1: 312.9 & $0.029,0.016$ & 0.2441 \\
\hline \multicolumn{5}{|l|}{ Block 3} \\
\hline GAAG & 0.597 & 297.7: 230.3, 207.0: 111.0 & $0.564,0.651$ & 0.0125 \\
\hline AGGA & 0.236 & 135.3: 392.7, 64.0: 254.0 & $0.256,0.201$ & 0.0674 \\
\hline AGAG & 0.146 & 83.8: 444.2, 40.0: 278.0 & $0.159,0.126$ & 0.1902 \\
\hline AAAG & 0.012 & $6.1: 521.9,4.0: 314.0$ & $0.012,0.013$ & 0.8831 \\
\hline
\end{tabular}


Table 4 Haplotype frequencies in a case-control cohort of patients with rheumatoid arthritis (Continued)

\begin{tabular}{|c|c|c|c|c|}
\hline Block 4 & & & & \\
\hline GAGGGGA & 0.6 & 296.8: 227.2, 207.0: 109.0 & $0.566,0.655$ & 0.0112 \\
\hline AGCAAAC & 0.202 & 120.9: 403.1, 49.0: 267.0 & $0.231,0.155$ & 0.0081 \\
\hline GGCAAGA & 0.149 & 83.0: 441.0, 42.0: 274.0 & $0.158,0.133$ & 0.3157 \\
\hline AGCAAGA & 0.022 & 10.1: 513.9, 8.0: 308.0 & $0.019,0.025$ & 0.5599 \\
\hline AGCAAAA & 0.017 & 6.0: 518.0, 8.0: 308.0 & $0.012,0.025$ & 0.1299 \\
\hline \multicolumn{5}{|l|}{ Block 5} \\
\hline GG & 0.669 & 344.6: 183.4, 220.9: 97.1 & $0.653,0.695$ & 0.2075 \\
\hline $\mathrm{AA}$ & 0.213 & 112.6: 415.4, 67.6: 250.4 & $0.213,0.213$ & 0.9829 \\
\hline$A G$ & 0.117 & 69.7: 458.3, 29.4: 288.6 & $0.132,0.092$ & 0.0828 \\
\hline \multicolumn{5}{|l|}{ Block 6} \\
\hline AA & 0.715 & 380.5: 145.5, 222.8: 95.2 & $0.723,0.701$ & 0.4774 \\
\hline$A G$ & 0.18 & 88.7: 437.3, 63.5: 254.5 & $0.169,0.200$ & 0.2564 \\
\hline GG & 0.1 & 53.3: 472.7, 31.5: 286.5 & $0.101,0.099$ & 0.9173 \\
\hline \multicolumn{5}{|l|}{ Block 7} \\
\hline AA & 0.699 & 374.8: 153.2, 216.9: 101.1 & $0.710,0.682$ & 0.3934 \\
\hline$A G$ & 0.214 & 110.9: 417.1, 70.1: 247.9 & $0.210,0.220$ & 0.7211 \\
\hline GG & 0.085 & 41.1: 486.9, 30.9: 287.1 & $0.078,0.097$ & 0.3288 \\
\hline \multicolumn{5}{|l|}{ Block 8} \\
\hline$A G$ & 0.531 & 294.0: 232.0, 153.8: 164.2 & $0.559,0.484$ & 0.0336 \\
\hline $\mathrm{AA}$ & 0.376 & 187.8: 338.2, 129.2: 188.8 & $0.357,0.406$ & 0.1518 \\
\hline GA & 0.092 & 42.9: 483.1, 34.8: 283.2 & $0.082,0.109$ & 0.1742 \\
\hline
\end{tabular}

Table 5 Haplotype frequencies in a case-control cohort of patients with ankylosing spondylitis

\begin{tabular}{|c|c|c|c|c|}
\hline Haplotype & Freq. & Case, control ratio counts & Case, control frequencies & $P$-value \\
\hline \multicolumn{5}{|l|}{ Block 1} \\
\hline AGGG & 0.755 & 75.0: 27.0, 242.0: 76.0 & $0.735,0.761$ & 0.5994 \\
\hline GAAA & 0.136 & 15.0: $87.0,42.0: 276.0$ & $0.147,0.132$ & 0.7006 \\
\hline AAGG & 0.1 & 11.0: 91.0, 31.0: 287.0 & $0.108,0.097$ & 0.7616 \\
\hline \multicolumn{5}{|l|}{ Block 2} \\
\hline AAAGAAG & 0.541 & 45.0: 57.0, 182.2: 135.8 & $0.441,0.573$ & 0.0198 \\
\hline GAAAGGA & 0.23 & 34.0: 68.0, 62.5: 255.5 & $0.333,0.196$ & 0.0043 \\
\hline GGGAGAG & 0.126 & 13.0: 89.0, 40.0: 278.0 & $0.127,0.126$ & 0.9686 \\
\hline GAAGAAG & 0.065 & 6.0: 96.0, 21.3: 296.7 & $0.059,0.067$ & 0.7731 \\
\hline \multicolumn{5}{|l|}{ Block 3} \\
\hline AGGAGGGGA & 0.609 & 49.7: 51.9, 206.0: 112.0 & $0.489,0.648$ & 0.0044 \\
\hline CGAGCAAAC & 0.187 & 29.8: 71.8, 49.0: 269.0 & $0.293,0.154$ & 0.0018 \\
\hline CAGGCAAGA & 0.134 & 14.3: $87.3,42.0: 276.0$ & $0.140,0.132$ & 0.829 \\
\hline CGAGCAAAA & 0.022 & 1.2: $100.4,8.0: 310.0$ & $0.012,0.025$ & 0.4324 \\
\hline CGAGCAAGA & 0.017 & 4.0: 97.6, 3.0: 315.0 & $0.039,0.010$ & 0.0408 \\
\hline CAAGCAAGA & 0.012 & 0.0: 101.6, 5.0: 313.0 & $0.000,0.016$ & 0.2042 \\
\hline \multicolumn{5}{|l|}{ Block 4} \\
\hline GG & 0.664 & 58.0: 44.0, 221.0: 97.0 & $0.569,0.695$ & 0.0187 \\
\hline $\mathrm{AA}$ & 0.228 & 28.0: $74.0,67.7: 250.3$ & $0.275,0.213$ & 0.1962 \\
\hline$A G$ & 0.108 & 16.0: 86.0, 29.3: 288.7 & $0.157,0.092$ & 0.067 \\
\hline \multicolumn{5}{|l|}{ Block 5} \\
\hline AAA & 0.523 & 45.9: 56.1, 173.7: 144.3 & $0.450,0.546$ & 0.0915 \\
\hline AGC & 0.29 & 33.3: 68.7, 88.6: 229.4 & $0.327,0.279$ & 0.3548 \\
\hline GGC & 0.097 & 7.6: $94.4,33.0: 285.0$ & $0.075,0.104$ & 0.3851 \\
\hline AAC & 0.072 & 10.7: 91.3, 19.4: 298.6 & $0.105,0.061$ & 0.1339 \\
\hline AGA & 0.013 & 4.1: 97.9, 1.3: 316.7 & $0.040,0.004$ & 0.0053 \\
\hline
\end{tabular}


Table 5 Haplotype frequencies in a case-control cohort of patients with ankylosing spondylitis (Continued)

\begin{tabular}{|c|c|c|c|c|}
\hline \multicolumn{5}{|l|}{ Block 6} \\
\hline AAA & 0.709 & 77.9: 24.1, 219.8: 98.2 & $0.764,0.691$ & 0.159 \\
\hline AGG & 0.101 & 9.5: $92.5,32.9: 285.1$ & $0.093,0.104$ & 0.7639 \\
\hline GGG & 0.096 & 9.4: 92.6, 30.9: 287.1 & $0.092,0.097$ & 0.8872 \\
\hline AGA & 0.084 & 5.0: 97.0, 30.1: 287.9 & $0.049,0.095$ & 0.1475 \\
\hline \multicolumn{5}{|l|}{ Block 7} \\
\hline $\mathrm{AA}$ & 0.683 & 70.0: 32.0, 217.0: 101.0 & $0.686,0.682$ & 0.9415 \\
\hline$A G$ & 0.221 & 23.0: 79.0, 70.0: 248.0 & $0.225,0.220$ & 0.9096 \\
\hline GG & 0.095 & 9.0: 93.0, 31.0: 287.0 & $0.088,0.097$ & 0.7819 \\
\hline \multicolumn{5}{|l|}{ Block 8} \\
\hline GAAGA & 0.49 & 53.9: 48.1, 151.8: 166.2 & $0.529,0.477$ & 0.3656 \\
\hline GAAAA & 0.198 & 21.1: 80.9, 62.1: 255.9 & $0.206,0.195$ & 0.8077 \\
\hline AAAAG & 0.14 & 14.0: 88.0, 44.9: 273.1 & $0.137,0.141$ & 0.9123 \\
\hline AAAAA & 0.059 & 3.0: 99.0, 22.0: 296.0 & $0.029,0.069$ & 0.14 \\
\hline ACGAA & 0.057 & 5.0: 97.0, 19.0: 299.0 & $0.049,0.060$ & 0.6831 \\
\hline AAGAA & 0.042 & 4.0: 98.0, 13.9: 304.1 & $0.039,0.044$ & 0.8369 \\
\hline \multicolumn{5}{|l|}{ Block 9} \\
\hline AT & 0.517 & 53.0: 49.0, 164.0: 154.0 & $0.520,0.516$ & 0.9455 \\
\hline GA & 0.28 & 26.6: 75.4, 91.0: 227.0 & $0.261,0.286$ & 0.6165 \\
\hline GT & 0.203 & 22.4: 79.6, 63.0: 255.0 & $0.220,0.198$ & 0.6357 \\
\hline \multicolumn{5}{|l|}{ Block 10} \\
\hline$A G$ & 0.802 & 78.2: 23.8, 258.5: 59.5 & $0.767,0.813$ & 0.3066 \\
\hline GA & 0.161 & 18.7: 83.3, 48.8: 269.2 & $0.184,0.153$ & 0.4683 \\
\hline GG & 0.032 & 3.8: $98.2,9.5: 308.5$ & $0.037,0.030$ & 0.7032 \\
\hline
\end{tabular}

Table 6 Allele and genotype frequencies in a case-control cohort of patients with RA

\begin{tabular}{|c|c|c|c|c|}
\hline dbSNP identity & $\begin{array}{c}\text { Allele/ } \\
\text { Genotype }\end{array}$ & No. of patients with RA (\%) & No. of controls (\%) & Fisher's $P$-value \\
\hline \multirow[t]{6}{*}{ rs2277105 } & $C$ & $1581(0.840)$ & $1512(0.848)$ & 0.491098 \\
\hline & $O(f r e q)$ & $19(0.010)$ & $12(0.007)$ & \\
\hline & $\mathrm{T}$ & $283(0.150)$ & $260(0.146)$ & \\
\hline & $\mathrm{CC}$ & $670(0.719)$ & $650(0.734)$ & 0.549842 \\
\hline & $C T$ & $241(0.259)$ & $212(0.239)$ & \\
\hline & $\pi$ & $21(0.023)$ & $24(0.027)$ & \\
\hline \multirow[t]{6}{*}{ rs11962800 } & A & $1568(0.831)$ & $1523(0.853)$ & 0.173781 \\
\hline & $O(f r e q)$ & $15(0.008)$ & $11(0.006)$ & \\
\hline & G & $304(0.161)$ & $251(0.141)$ & \\
\hline & $\mathrm{AA}$ & $656(0.701)$ & $656(0.740)$ & 0.184145 \\
\hline & AG & $256(0.274)$ & $211(0.238)$ & \\
\hline & GG & $24(0.026)$ & $20(0.023)$ & \\
\hline \multirow[t]{6}{*}{ rs443861 } & A & $357(0.190)$ & $275(0.154)$ & 0.00832 \\
\hline & $\mathrm{O}($ freq $)$ & $19(0.010)$ & $12(0.007)$ & \\
\hline & G & $1507(0.800)$ & $1497(0.839)$ & \\
\hline & AA & $51(0.055)$ & $26(0.029)$ & 0.01011 \\
\hline & $A G$ & $255(0.274)$ & $223(0.252)$ & \\
\hline & GG & $626(0.672)$ & $637(0.719)$ & \\
\hline \multirow[t]{6}{*}{ rs369086 } & A & $485(0.257)$ & $460(0.258)$ & 0.510123 \\
\hline & $O(f r e q)$ & $18(0.010)$ & $11(0.006)$ & \\
\hline & G & $1381(0.733)$ & $1314(0.736)$ & \\
\hline & $\mathrm{AA}$ & $61(0.065)$ & $71(0.080)$ & 0.260584 \\
\hline & $A G$ & $363(0.389)$ & $318(0.359)$ & \\
\hline & GG & $509(0.546)$ & $498(0.561)$ & \\
\hline
\end{tabular}


rs1043784, rs7764128, rs1225934 and rs8643 were not significantly associated with RA and AS.

\section{Conclusions}

Our study demonstrated significantly increased TXNDC5 expression in the synovium and blood of RA patients, which may contribute to the irregular angiogenesis and abnormal cell differentiation observed in the synovial membrane. The study also revealed the genetic effect of TXNDC5 on RA and AS risk.

\section{Additional material}

Additional file 1: Supplementary materials and methods. This table summarizes the clinical data of patients with RA, OA and AS.

Additional file 2: Supplementary results. This table provides the raw microarray data to perform association, LD and haplotype analysis. We genotyped 96 SNPs across the TXNDC5 gene from 267 Han Chinese patients with RA, 51 patients and 160 control individuals. All SNPs yielded genotype data, and the study sample success rate was $99.1 \%$.

\section{Abbreviations}

AS: ankylosing spondylitis; DMARD: disease-modifying anti-rheumatic drug; KLH: keyhole limpet hemocyanin; LD: linkage disequilibrium; MAF: minor allele frequencies; NSAID: non-steroidal anti-inflammatory drugs; NSV: nonsegmental vitiligo; OA: osteoarthritis; PDI: disulfide isomerase domain; RA: rheumatoid arthritis; SDS-PAGE: sodium dodecyl sulphate polyacrylamide gel electrophoresis; SLE: systemic lupus erythematosus; SNP: single nucleotide polymorphism; TXNDC5: Thioredoxin domain containing 5; UTR: untranslational regions

\section{Acknowledgements}

This study was supported by the National Natural Science Foundation of China (NTFC) (30972720), the National Basic Research Program of China (2010CB529105), the Provincial Natural Science Foundation of Shandong (ZR2010CM1032, Y2007C132, Y2008C130) and the Shandong Taishan Scholarship.

\section{Author details}

'National Laboratory for Bio-Drugs of Ministry of Health, Provincial Laboratory for Modern Medicine and Technology of Shandong, Research Center for Medicinal Biotechnology, Shandong Academy of Medical Sciences, Jingshi Road 18877, Jinan, Shandong, 250062. P. R. China. ${ }^{2}$ Orthopedic Surgery Center of Shandong Qianfoshan Hospital. Jingshi Road 16766, Jinan, Shandong, 250014. P. R. China.

\section{Authors' contributions}

$X C$ designed and executed the study and prepared the manuscript. JP and KF performed the genotyping. YZ and LW performed the Western blots and real time PCR. XY collected tissue samples. All authors have read and approved the final manuscript for publication.

\section{Competing interests}

The authors declare that they have no competing interests.

Received: 11 January 2011 Revised: 24 February 2011

Accepted: 29 July 2011 Published: 29 July 2011

\section{References}

1. Edman $J C$, Ellis $L$, Blacher RW, Roth RA, Rutter WJ: Sequence of protein disulphide isomerase and implications of its relationship to thioredoxin. Nature 1985, 317:267-270.

2. Freedman RB, Hirst TR, Tuite MF: Protein disulphide isomerase: building bridges in protein folding. Trends Biochem Sci 1994, 19:331-336.
3. Knoblach B, Keller BO, Groenendyk J, Aldred S, Zheng J, Lemire BD, Li L, Michalak M: ERp19 and ERp46, new members of the thioredoxin family of endoplasmic reticulum proteins. Mol Cell Proteomics 2003, 2:1104-1109.

4. Charlton HK, Webster J, Kruger S, Simpson F, Richards AA, Whitehead JP: ERp46 binds to AdipoR1, but not AdipoR2, and modulates adiponectin signalling. Biochem Biophys Res Commun 2010, 392:234-239.

5. Veale DJ, Fearon U: Inhibition of angiogenic pathways in rheumatoid arthritis: potential for therapeutic targeting. Best Pract Res Clin Rheumatol 2006, 20:941-947.

6. Chang X, Cui Y, Zong M, Zhao Y, Yan X, Chen Y, Han J: Identification of proteins with increased expression in rheumatoid arthritis synovial tissues. J Rheumatol 2009, 36:872-880.

7. Muz B, Khan MN, Kiriakidis S, Paleolog EM: The role of hypoxia and HIF-dependent signaling events in rheumatoid arthritis. Arthritis Res Ther 2009, 11:201.

8. Hitchon CA, El-Gabalawy HS, Bezabeh T: Characterization of synovial tissue from arthritis patients: a proton magnetic resonance spectroscopic investigation. Rheumatol Int 2009, 29:1205-1211.

9. The International HapMap Consortium: The International HapMap Project. Nature 2003, 426:789-796.

10. The International HapMap Consortium: Integrating ethics and science in the International HapMap Project. Nat Rev Genet 2004, 5:467-475.

11. Barrett JC, Fry B, Maller J, Daly MJ: Haploview: analysis and visualization of LD and haplotype maps. Bioinformatics 2005, 21:263-265.

12. Li Z, Zhang Z, He Z, Tang W, Li T, Zeng Z, He L, Shi Y: A partition-ligationcombination-subdivision EM algorithm for haplotype inference with multiallelic markers: update of the SHEsis. Cell Res 2009, 19:519-523.

13. Alivernini S, Fedele AL, Cuoghi I, Tolusso B, Ferraccioli G: Citrullination: the loss of tolerance and development of autoimmunity in rheumatoid arthritis. Reumatismo 2008, 60:85-94.

14. Senolt L, Pavelka K, Housa D, Haluzík M: Increased adiponectin is negatively linked to the local inflammatory process in patients with rheumatoid arthritis. Cytokine 2006, 35:247-252.

15. Frommer KW, Zimmermann B, Meier FM, Schröder D, Heil M, Schäffler A, Büchler C, Steinmeyer J, Brentano F, Gay S, Müller-Ladner U, Neumann E: Adiponectin-mediated changes in effector cells involved in the pathophysiology of rheumatoid arthritis. Arthritis Rheum 2010, 62:2886-2899.

16. Choi HM, Lee YA, Lee SH, Hong SJ, Hahm DH, Choi SY, Yang HI, Yoo MC, Kim KS: Adiponectin may contribute to synovitis and joint destruction in rheumatoid arthritis by stimulating vascular endothelial growth factor, matrix metalloproteinase-1, and matrix metalloproteinase-13 expression in fibroblast-like synoviocytes more than proinflammatory mediators. Arthritis Res Ther 2009, 11:R161.

17. Tian F, Zhou X, Wikström J, Karlsson H, Sjöland H, Gan LM, Borén J, Akyürek LM: Protein disulfide isomerase increases in myocardial endothelial cells in mice exposed to chronic hypoxia: a stimulatory role in angiogenesis. Am J Physiol Heart Circ Physiol 2009, 297:H1078-1086.

18. Jeong KH, Shin MK, Uhm YK, Kim HJ, Chung JH, Lee MH: Association of TXNDC5 gene polymorphisms and susceptibility to nonsegmental vitiligo in the Korean population. Br J Dermatol 2010, 162:759-764.

19. Lin SH, Liu CM, Liu YL, Shen-Jang Fann C, Hsiao PC, Wu JY, Hung SI, Chen CH, Wu HM, Jou YS, Liu SK, Hwang TJ, Hsieh MH, Chang CC, Yang WC, Lin JJ, Chou FH, Faraone SV, Tsuang MT, Hwu HG, Chen WJ: Clustering by neurocognition for fine mapping of the schizophrenia susceptibility loci on chromosome 6p. Genes Brain Behav 2009, 8:785-794.

doi:10.1186/ar3429

Cite this article as: Chang et al.: Investigating a pathogenic role for TXNDC5 in rheumatoid arthritis. Arthritis Research \& Therapy 2011 13:R124. 